\title{
ACEITAÇÃO-REJEIÇÃO PARA ESTUDAR E AGRESSIVIDADE NA ESCOLA
}

Fermino Fernandes Sisto*

\begin{abstract}
RESUMO. Foram estudadas as relações entre agressividade e aceitação-rejeição em 1281 estudantes de quatro escolas de ensino fundamental. A medida sociométrica baseou-se em três escolhas positivas e três negativas em situação de estudo. As escalas de agressividade forneceram três medidas: em situação familiar, em situação escolar e geral. Nas medidas sociométrica e de agressividade em situação familiar as diferenças entre as escolas foram atribuídas ao acaso. As escalas de agressividade escolar e geral formaram dois subgrupos, sendo duas escolas com menor e outras duas com maior agressividade. Foram encontradas correlações significativas entre as medidas sociométrica e de agressividade escolar nas quatro escolas e com agressividade geral em uma delas, indicando que quanto maior a aceitação social, menor a agressividade. Como as correlações foram baixas, estudaram-se grupos extremos em termos de aceitação-rejeição e apenas em uma escola as escalas de agressividade escolar e geral diferenciaram esses grupos.
\end{abstract}

Palavras-chave: agressividade, aceitação-rejeição de pares, escola.

\section{PEER ACCEPTANCE-REJECTION TO STUDY AND AGGRESSIVENESS AT SCHOOL}

\begin{abstract}
The relationship between aggressiveness and peer acceptance-rejection were analyzed in 1281 elementary school children. Sociometric measure was based on three positive and three negative classmates choices. The aggressiveness scales gathered information about familiar, scholar and general situations. There were no statistically insignificant differences among the schools related to the sociometric and aggressiveness in familiar situation measures. The scales of the scholar and general aggressiveness formed two sub-groups, in which two schools showed less aggressiveness and the two other more aggressiveness. Scholar aggressiveness showed significant correlations with the sociometric status in all schools and the general aggressiveness in one of them, suggesting that the most social acceptance, the lesser the student's aggressiveness. As the correlations were low, extreme groups in acceptance-rejection conditions had been studied and the scales of scholar and general aggressiveness had differentiated these groups in only one school.
\end{abstract}

Key words: aggressiveness, peer acceptance-rejection, school.

A violência e a agressão nas escolas são problemas em muitos países, e como exemplos de estudos pode-se citar: no Canadá o de Boivin (1998), na Austrália o de Rigby e Slee (1991), na Inglaterra os de Boulton e Underwood (1992) e na Escandinávia, os de Olweus (1991, 1993). Há muito mais relatos desse problema em relação às escolas de Estados Unidos (Ladd, Kochenderfer, \& Coleman, 1997, entre outros).

A demanda por segurança dos moradores das periferias de cidades brasileiras dos anos $1980 \mathrm{fez}$ emergir o interesse pelo fenômeno da violência nas escolas. A mídia expôs as condições precárias dos prédios, sua necessidade de proteção, as constantes depredações dos edifícios e invasões (Sposito, 2001). $\mathrm{O}$ clima de insegurança agravou-se com a intensificação da ação do crime organizado e do tráfico em algumas cidades brasileiras, os quais, na literatura, são considerados as grandes causas da violência nas escolas públicas (Costa, 1993; Guimarães, 1995; Rodrigues, 1994).

Houve investigações que estudaram os efeitos da banalização da violência sobre a sociabilidade dos alunos e sugeriram que a existência de um clima tenso entre adultos e adolescentes ou entre alunos afetaria a atividade escolar (Cardia, 1997; Costa, 1993; Rodrigues, 1994). Por sua vez, Abramovay, Rua,

* Pedagogo, doutor pela Universidad Complutense de Madrid, Livre-Docente em Psicologia do Desenvolvimento pela Universidade Estadual de Campinas, é professor titular aposentado da UNICAMP e professor da Universidade São Francisco no Programa de Estudos Pós-Graduados em Psicologia. 
Waiselfisz e Andrade (1999) mostraram que para $37,3 \%$ dos jovens a escola não era local de violência; quase metade considerou-a de média violência e 16\%, de muita violência. Para esses jovens, os bailes, festas, televisão e shows eram muito violentos e $75 \%$ dos entrevistados indicaram a família como local de nãoviolência. Em contraposição, Meneghel, Giuglian e Falceto (1998) pesquisaram a violência doméstica e constataram que as punições físicas graves, freqüentes ou ocasionais, foram acontecimentos presentes em $53,9 \%$ dos estudantes, sendo que $37 \%$ delas ocorreram com estudantes de escolas particulares e $67 \%$ com alunos de escolas públicas. Os episódios graves e freqüentes foram semelhantes em ambos os tipos de escola.

Candau (1999) apontou a prática de agressões físicas e verbais entre os alunos como muito freqüente e também comum por parte de funcionários e professores. As depredações e agressões ao patrimônio também foram relatadas, sendo menor a frequiência de roubo e intimidação de pessoas externas à escola. Dois outros estudos (Costa, 2000; Paim Costa, 2000) registraram agressões verbais em escolas com alto grau de violência. As rivalidades entre grupos juvenis retratavam a segmentação de territórios $\mathrm{e}$ as brigas entre os alunos afetaram o projeto educativo da escola. Também Araújo (2000) estudou a violência na escola como produto da rivalidade de bairros. Investigou as formas de constituição da identidade dos adolescentes que se impuseram pelo medo ou força em razão do estigma de sua moradia. Assim, a violência observada na escola não foi exclusivamente reação à instituição, mas demarcação de espaços de poder.

No levantamento nacional realizado por Codo (1999), as situações mais freqüentes relatadas por professores foram depredações, furtos ou roubos em relação à escola, agressões físicas entre alunos e agressões de alunos contra professores. Constatou-se que nas escolas com mais de 2.200 alunos a depredação era comum, exceto nas capitais. Comparando-se os estados, os índices de vandalismo, furtos e roubos variaram entre $33 \%$ e $68 \%$; as agressões a alunos dentro da escola foram de $8,5 \%$ até $58,6 \%$; e a professores, dentro das escolas, de $1,2 \%$ a $33 \%$. As práticas de agressão, tanto entre os alunos como contra os professores, foram mais comuns nos estabelecimentos de grande porte e nas capitais.

Em seu estudo, Waiselfisz (1998) indicou que os meninos participaram mais de situações de agressão física, discussão e ameaça ou intimidação no interior da escola. A situação mais freqüente foi a discussão (quase $55 \%$, com pouca diferença entre meninos e meninas); as ameaças e intimidações envolveram $28 \%$ dos meninos e apenas $10 \%$ das meninas; e as agressões físicas ocorreram muito pouco, pois $72 \%$ dos jovens e $93 \%$ das jovens nunca se envolveram. A relação entre agressividade na adolescência e punição física grave foi significativa, sendo que adolescentes agressivos foram mais punidos. Nesse estudo, o abuso físico foi maior entre adolescentes do sexo masculino, mais velhos, na presença de violência entre irmãos, procedentes de famílias de baixa renda e rígidas. Como no estudo de Meneghel, Giuglian e Falceto (1998), os resultados dessa pesquisa sugeriram que os comportamentos agressivos de adolescentes seriam conseqüência da violência doméstica, pois o adolescente agressivo na escola era um indivíduo maltratado.

Santos (1999) estudou os episódios de violência na escola e o maior índice foi o de agressões contra a pessoa (60\% das ocorrências), compreendendo as lesões corporais, roubo (carros, dinheiro), brigas e invasões no espaço escolar. Ao lado disso, Camacho (2000) concluiu que os alunos das escolas de elite optaram por práticas de agressão na sala de aula, sobretudo verbais e de maneira dissimulada, enquanto $\mathrm{q}$ os das escolas públicas manifestaram agressões verbais e físicas no recreio. Nas escolas particulares o foco das práticas de violência foram os negros, os mais gordos e feios e os suspeitos de homossexualidade; na escola pública os grupos com diferentes estilos ou membros de gangues agrupavamse para agredir verbal e fisicamente seus colegas. Há também uma pesquisa (Illanud, 2000) que abordou a vítima da violência ou agressão. Os tipos mais freqüentes de vitimização foram o furto de objetos de pequeno valor dentro da escola $(48,1 \%$ dos alunos), ameaça de agressão $(36,5 \%)$, pertences danificados $(33,1 \%)$ e agressão física por colega $(4,6 \%)$.

Um aumento da violência na escola destaca a necessidade de compreender a dinâmica do conflito dos pares agressivos, pois geralmente a violência está associada a outras condutas, como rejeição entre colegas ou pares, fracasso escolar, delinqüência e abuso de drogas (Kupersmidt \& Coie, 1990). Crianças agressivas não populares exibem mais comportamentos desatentos ou fora da tarefa dada (Lochman \& Lampron, 1985) e mais comportamentos imaturos em relação às crianças agressivas e aceitas entre pares (Dubow, 1988).

No contexto escolar a agressividade pode conduzir à rejeição por colegas ou pares (Dodge, Bates, \& Pettit, 1990) e possibilitaria relações com pares marginais, os quais, no começo da adolescência, facilitariam o caminho para atividades delinqüentes 
(Cairns, Cairns, Neckerman, Ferguson, \& Gariepy, 1989; por exemplo). No entanto, os estudos de Bierman, Smoot e Aumiller, (1993) e Coie, Terry, Lenox, Lochman e Hyman (1996), entre outros, concluíram que metade das crianças fisicamente agressivas na escola elementar foi rejeitada por seus pares, levando-os a enfatizar que nem todas as crianças agressivas se relacionaram com colegas problemáticos.

Newcomb, Bukowski e Pattee (1993), em uma metaanálise, estudaram 41 trabalhos. Seus resultados mostraram que crianças populares receberam mais indicações positivas de colegas, enquanto os níveis elevados da agressão, níveis baixos de sociabilidade e habilidades cognitivas foram associados à rejeição de colegas.

Em relação à família, Huesman, Eron, Ledfkowitz e Walder (1984) encontraram que crianças agressivas de 8 anos repetiam as práticas de seus próprios pais quando avaliadas aos 30 anos. Outras evidências de que as crianças adotaram muitos padrões de interação social vividos no contexto da família foram apresentadas na pesquisa de Parke, Cassidy, Burks, Carson e Boyum (1992), entre outras. As crianças expostas a interações agressivas com suas mães e entre seus pais tenderam a ser agressivas, aumentando a probabilidade de que seus pares ou colegas não gostassem dela (Patterson, 1982).

No geral, as crianças foram avaliadas, nas pesquisas brasileiras ou estrangeiras, com base nas informações fornecidas por professores. Além disso, raramente forneceram a incidência do fenômeno em relação à quantidade de alunos da escola.

Nesse contexto, pode-se perguntar até que ponto os professores conseguem identificar o comportamento agressivo de seus estudantes. Freqüentemente solicitados a identificar e referir crianças com problemas de comportamento, eles podem não avaliar os comportamentos agressivos de alguns estudantes que ou não exibiram tal conduta perto deles ou foram pouco intensos em relação ao impacto social; ou os professores simplesmente não perceberam problemas. Ao lado disso, também se considera que as crianças têm mais possibilidade de se engajar em agressão quando não há supervisão do professor. Também, Ollendick, Oswald e Francis (1989) encontraram que indicações de estudantes agressivos, feitas por professores e pares, foram relativamente incongruentes. Essas situações sugerem que a percepção de professores pode não ser precisa, indicando que a percepção do aluno em relação a si mesmo pode se uma outra vertente para se analisar a problemática.
Há que considerar também que as pesquisas mostram terem as estimativas dos professores do status sociométrico mais positivas para meninas do que para meninos e variado de acordo com preferências pessoais (Grondlund, 1950). Novamente, o status sociométrico estabelecido entre as escolhas do próprio grupo pode fornecer informações interessantes para serem analisadas.

Assim, outra forma de coletar essas informações é solicitar que os próprios alunos emitam sua percepção sobre sua agressividade e eles próprios façam suas escolhas para a indicação do nível de aceitaçãorejeição entre eles. No entanto, neste estudo não se pretende investigar qual a melhor forma de se avaliar esses dois aspectos, pois ambos apresentam inconvenientes, mas estudar a problemática de um outro ângulo. De fato, ele se propôs comparar quatro escolas com características diferentes, com base em informações fornecidas pelos participantes, quanto à agressividade e aceitação-rejeição dos estudantes de segundas, terceiras e quartas séries.

\section{MÉTODO}

\section{Participantes}

Participaram voluntariamente da pesquisa 1281 estudantes de quatro escolas, $82 \%$ do total de alunos que freqüentavam as segundas, terceiras e quartas séries. Três delas eram estaduais, sendo duas de periferia, e a quarta, particular. Os dados descritivos, por séries, encontram-se na Tabela 1.

Tabela 1. Dados Descritivos dos Participantes por Séries

\begin{tabular}{|c|c|c|c|}
\hline & Segunda série & Terceira série & Quarta série \\
\hline$n$ & 472 & 501 & 308 \\
\hline idade & 7 a 13 anos & 8 a 16 anos & 9 a 16 anos \\
\hline média & 8,4 & 9,4 & 10,6 \\
\hline desvio padrão & 0,70 & 0,85 & 0,94 \\
\hline gênero masculino & $224(47,5 \%)$ & $279(55,7 \%)$ & $152(49,4 \%)$ \\
\hline gênero feminino & $248(52,5 \%)$ & $222(44,3 \%)$ & $156(50,6 \%)$ \\
\hline
\end{tabular}

Como pode ser observado na Tabela 1, os intervalos das idades variaram, assim como suas médias. Como o desvio foi pequeno, interpretouse que as freqüências das idades das crianças se concentraram em torno dessas médias. Assim, houve uma tendência de as crianças estarem freqüentando a série esperada, em razão de suas idades. 


\section{Características das escolas}

\section{Escola A}

Está localizada em um bairro da periferia de Campinas, de classe baixa e composto de casas populares. Além da infra-estrutura necessária, a escola possuía sala de reforço, sala de vídeo, biblioteca, quadra de esportes e estacionamento reservado para professores. A escola era freqüentada por mais de 1000 alunos e as salas eram de 40 alunos, em média. Muitos alunos eram tidos como indisciplinados e havia muita falta. As professoras acreditavam que "essas crianças estavam ali para incomodar, porque os pais não agüentavam seus filhos em casa, e pela merenda oferecida" e se diziam que elas "não tinham jeito". A escola tinha uma aparência de desorganizada, sugerindo a necessidade de limpeza e reforma.

\section{Escola B}

Está localizada em um bairro antigo da cidade de Campinas, de classe baixa, porém sem favela ou casas populares. Além da infra-estrutura necessária, a escola possuía sala de vídeo, biblioteca e quadra de esportes. Freqüentavam a escola mais de 500 alunos, com 30-38 alunos em sala, todos com uniformes limpos. Era uma escola limpa e aparentemente organizada. Na hora da saída, muitos pais esperavam seus filhos ou havia uso de perua escolar. A direção e professores pareciam preocupados com a educação e em melhorar a escola. Havia projetos de conscientização da coleta de lixo, prevenção de acidentes e outros, mas não eventos extra-escolares. Tudo indicou que os alunos indisciplinados participavam das aulas normalmente.

\section{Escola D}

dstá localizada em um bairro periférico da cidade de Americana, de classe média baixa. Contava com mais de 500 alunos e 30-35 alunos por sala, e os estudantes usavam uniformes limpos. Era uma escola limpa e aparentemente organizada. Além da infraestrutura necessária, possuía sala de jogos, sala de vídeo, biblioteca, sala de almoxarifado e quadra de esportes. $\mathrm{Na}$ entrada tinha flores e painéis com atividades das crianças. A direção e os professores pareciam estar preocupados com a educação e em melhorar a escola. Quanto aos alunos indisciplinados, tudo indicou que eles participavam das aulas normalmente.

\section{Escola E}

Está localizada no centro de Campinas e tem como mantenedora uma entidade religiosa, caracterizando-se como uma escola particular. Com
500 alunos, de 20 a 30 alunos em sala, todos usavam uniformes limpos. Era uma escola bastante limpa e organizada. Além da infra-estrutura necessária, a escola possuía sala de jogos, sala de vídeo, biblioteca, quadra de esportes e sala de almoxarifado. Aparentemente os alunos tidos como indisciplinados eram poucos e passavam despercebidos nas visitas feitas. Professores acompanhavam todas as atividades dos alunos, tanto em sala de aula como fora dela. $\mathrm{O}$ comprometimento com a qualidade da educação era nítido.

\section{Instrumentos}

Foram realizados dois tipos de medida, ambos coletivamente e na sala de aula dos alunos. A ordem de aplicação foi indicada por sorteio para cada sala de aula.

\section{Medida sociométrica}

Essa medida teve por objetivo detectar em que a extensão uma criança é escolhida ou rejeitada para uma atividade por seus colegas de classe. Para isso, solicitou-se que os alunos indicassem, pela ordem de preferência, três colegas de sua sala de aula com os quais gostariam de estudar . Realizada essa parte, foi pedido que indicassem, também pela ordem de rejeição, outros três colegas, igualmente de sua sala de aula, com os quais não gostariam de estudar. As indicações positivas receberam pontos positivos $(+3$, +2 e +1 , respectivamente) e as negativas, pontos negativos $(-3,-2$ e -1 , respectivamente). A posição sociométrica foi indicada pela soma aritmética dos pontos recebidos em razão das escolhas, positivas e negativas.

\section{Escala de Agressividade}

A Escala de Agressividade para crianças e jovens (Sisto \& Bazi, 2000) fornece três tipos de medidas, quais sejam, a agressividade em situação familiar, a agressividade em situação escolar e uma medida de agressividade geral, soma das outras duas subescalas. A terceira medida é possível, pois em sua construção foram isolados por análise de componente principal dois fatores, um relacionado à situação familiar e outro à situação escolar. Para a subescala de agressividade em situação familiar, o valor de alfa encontrado foi de 0,7560; para a subescala de agressividade em situação o valor de alfa foi de 0,7097; e para a escala geral, 0,7983 .

$\mathrm{O}$ instrumento consta de 16 afirmativas - 8 referentes à situação escolar e outras 8 referentes à situação familiar - para as quais os sujeitos deverão responder sim ou não. Exemplos de situações para 
agressividade em situação familiar: Gosto de ameaçar meus irmãos ( ) sim ( ) não; Quando meus familiares gritam comigo, também grito com eles ( ) sim ( ) não. Exemplos de situação para agressividade em situação escolar: Implico com as pessoas da minha escola ( ) sim ( ) não; Machuco meus colegas da escola quando tenho vontade ( ) sim ( ) não.

Para cada resposta sim é atribuído 1 (um) ponto e não se atribui pontuação à resposta não. Assim, as subescalas de agressividade em situação escolar e em situação familiar variam de zero a 8 pontos cada uma, e a de agressividade geral, de zero a 16 pontos.

Para a aplicação, cada aluno tinha um exemplar do teste, que continha as afirmativas e o local onde deveriam assinalar a alternativa (sim ou não) pretendida. Cada afirmativa foi lida em voz alta pelo aplicador e deu-se tempo suficiente para que cada um assinalasse a resposta. O tempo médio de aplicação variou entre 9 e 13 minutos, e com as instruções e o preenchimento, variou de 15 a 20 minutos, em razão da série escolar.

\section{RESULTADOS}

As análises dos dados foram feitas em termos descritivos, por correlação ou diferença de médias para dois ou mais grupos, dependendo da situação. O nível de significância adotado foi 0,05 .

Os dados descritivos de cada escola, em relação à medida sociométrica, encontram-se na Tabela 2. A escola que teve maior amplitude entre as pontuações da sociometria foi a escola A e a menor amplitude, a escola B.

Tabela 2. Estatística Descritiva da Medida Sociométrica por Escola

\begin{tabular}{lcccc}
\hline & Escola A & Escola B & Escola D & Escola E \\
\hline média & 0,42 & 0,18 & 0,50 & 0,0 \\
desvio padrão & 10,23 & 8,73 & 8,55 & 9,19 \\
mínimo & -53 & -28 & -32 & -38 \\
máximo & 29 & 25 & 40 & 23 \\
\hline
\end{tabular}

As médias ficaram próximas de zero, todas positivas, indicando que a tendência, ainda que incipiente, foi de maior aceitação em comparação à rejeição. Por meio da análise de variância Anova, constatou-se que as diferenças entre as escolas podem ser atribuídas ao acaso $[F(3,1278)=0,131$ e $p=0,971]$.

Os dados descritivos de cada escola, em relação às medidas de agressividade, encontram-se na Tabela 3. Com relação à escala de agressividade familiar, foram observadas pontuações em toda e extensão da escala, ou seja, zero a 8 pontos, em todas as escolas. Apesar da variação das médias, as diferenças foram atribuídas ao acaso em razão da análise de variância $(F=2,096$ e $p=0,079)$.

Tabela 3. Estatística Descritiva das Escalas de Agressividade por Escola

\begin{tabular}{|c|c|c|c|c|c|}
\hline & & Escola A & Escola B & Escola D & Escola E \\
\hline \multirow{4}{*}{$\begin{array}{l}\text { Agressividade } \\
\text { familiar }\end{array}$} & média & 2,77 & 3,07 & 2,80 & 3,26 \\
\hline & $\mathrm{e}^{\text {desvio padrão }}$ & 1,97 & 2,17 & 1,95 & 2,21 \\
\hline & mínimo & 0 & 0 & 0 & 0 \\
\hline & máximo & 8 & 8 & 8 & 8 \\
\hline \multirow{4}{*}{$\begin{array}{l}\text { Agressividade } \\
\text { escolar }\end{array}$} & média & 0,76 & 1,39 & 1,06 & 1,52 \\
\hline & e desvio padrão & 1,55 & 1,84 & 1,47 & 1,72 \\
\hline & mínimo & 0 & 0 & 0 & 0 \\
\hline & máximo & 8 & 8 & 8 & 8 \\
\hline \multirow{4}{*}{$\begin{array}{l}\text { Agressividade } \\
\text { geral }\end{array}$} & média & 3,53 & 4,60 & 3,77 & 4,72 \\
\hline & e desvio padrão & 2,77 & 3,58 & 2,86 & 3,48 \\
\hline & mínimo & 0 & 0 & 0 & 0 \\
\hline & máximo & 12 & 16 & 15 & 16 \\
\hline
\end{tabular}

No caso da escala de agressividade escolar, todas as escolas tiveram pontuação mínima de zero e pontuação máxima de 8 , em uma escala com possibilidade de 0 a8. Diferentemente da agressividade familiar, a análise de variância indicou que as diferenças de médias não puderam ser atribuídas ao acaso $[F(3,1278)=14,417$ e $p=0,000]$. Pela prova de Tukey foram encontrados dois subconjuntos, quais sejam, menor agressividade (escolas A e D) e maior agressividade (escolas E e B).

Por fim, no que tange à escala de agressividade geral, todas as escolas tiveram pontuação mínima de zero, mas apenas duas escolas (B e E) alcançaram a pontuação máxima da escala, qual seja, 16. A análise de variação indicou que as diferenças de média não podem ser atribuídas ao acaso $[F(3,1278)=6,998$ e $p=0,000]$. Pela prova de Tukey foram encontrados dois subconjuntos, quais sejam, menor agressividade (escolas A e D) e maior agressividade (escolas E e B).

A Tabela 4 fornece os coeficientes de correlação de Pearson entre as medidas sociométrica e de agressividade. Em relação à escala de agressividade familiar e aceitação/rejeição de pares, não foi encontrada nenhuma correlação que alcançasse o nível de significância esperado, o que sugeriu uma independência da percepção de sua agressividade com a família e o fato de ser aceito ou rejeitado para estudar entre seus companheiros de classe.

Não obstante, as pontuações da agressividade escolar se correlacionaram negativa e 
significativamente com as pontuações da medida sociométrica. Esse dado sugere que, quanto maior a aceitação social, menor a agressividade escolar declarada pelo estudante.

Tabela 4. Coeficientes de Correlação de Pearson de Pearson (r) e Níveis de Significância (p), Por Escola, entre Pontuações de Agressividade e Pontuações Sociométricas

\begin{tabular}{lccccc}
\hline & & Escola A & Escola B & Escola D & Escola E \\
\hline $\begin{array}{l}\text { Agressividade } \\
\text { familiar }\end{array}$ & $\mathrm{r}$ & $-0,008$ & $-0,109$ & $-0,069$ & $-0,027$ \\
\hline Agressividade & $\mathrm{p}$ & 0,872 & 0,261 & 0,173 & 0,736 \\
escolar & $\mathrm{r}$ & $-0,155$ & $-0,252$ & $-0,140$ & $-0,159$ \\
\hline $\begin{array}{l}\text { Agressividade } \\
\text { geral }\end{array}$ & $\mathrm{p}$ & $-0,002^{*}$ & $0,009^{*}$ & $0,005^{*}$ & $0,045^{*}$ \\
\hline
\end{tabular}

Por fim, com relação à medida de agressividade geral, apenas na escola B a correlação com a aceitação/rejeição entre pares mostrou-se significativa e negativa. A tendência indicada foi que ao aumento da aceitação lhe corresponde uma diminuição da agressividade geral declarada.

Considerando o fato de que as correlações significativas encontradas foram baixas, decidiu-se analisar se os grupos extremos de aceitação/rejeição se diferenciariam em razão das escalas de agressividade. O critério para constituição dos grupos extremos foi fixado com base em todas as pontuações da medida sociométrica, ou seja, independentemente das escolas, selecionaram-se os $25 \%$ dos participantes com as maiores pontuações negativas e os $25 \%$ dos sujeitos com as maiores pontuações positivas. Para constatar se esse critério mudara consistentemente a características das escolas, foi feita uma análise por quiquadrado, considerando-se as categorias rejeitado e aceito, por um lado e, por outro, as escolas. A prova indicou que as diferenças poderiam ser atribuídas ao acaso $\left(\chi^{2}=3,404, g l=4\right.$ e $\left.p=0,493\right)$.

A fim de verificar se as diferenças de média das escalas de agressividade em cada escola, em razão dos grupos extremos formados pela medida sociométrica, eram significativas, foi usada a prova t de student. Apenas na escola B as escalas de agressividade escolar $(t=2,316 \mathrm{e}$ $p=0,025)$ e agressividade geral $(t=2,310$ e $p=0,025)$ diferenciaram os grupos extremos. As diferenças entre as escolas por grupos extremos e medidas de agressividade também foram estudadas por meio da análise de variância Manova (4x2). No caso da agressividade familiar não foram encontradas diferenças significativas para escola $[F(3,635)=1,698$ e $p=0,195]$, nem para aceitação/rejeição $[F(1,637)=1,840$ e $p=0,175]$, com também não houve efeito de interação $[F(3,635)=0,950$ e $p=0,434]$. Em se tratando da agressividade escolar, foram encontradas diferenças significativas para aceitação/rejeição $[F(1,637)=17,318$ e $p=0,000]$ e escola $[F(3,635)=8,384$ e $p=0,000]$, mas não para o efeito de interação $[F(3,635)=0,943$ e $p=0,439]$. Por fim, para a agressividade geral foram encontradas diferenças significativas para aceitação/rejeição $[F(1,637)=9,736$ e $p=0,002]$ e escola $[F(3,635)=6,533$ e $p=0,000]$, mas não para o efeito de interação $[F(3,635)=1,160$ e $p=0,328]$. A tendência para a formação dos subgrupos permaneceu a mesma.

\section{DISCUSSÃO E CONCLUSÃO}

Este estudo teve como objetivo comparar quatro escolas com características diferentes, quanto à agressividade e aceitação-rejeição dos estudantes de segunda, terceira e quarta séries do ensino fundamental. Seu diferencial em relação aos estudos levantados na literatura refere-se ao fato de que se valeu de informações fornecidas pelos participantes, em outros termos, trabalhou com autopercepção.

As médias da medida sociométrica, apesar de positivas, sugeriram uma tendência incipiente de maior aceitação dos participantes por seus pares. Também, as diferenças entre as pontuações das escolas foram pequenas, a ponto de serem atribuídas ao acaso. Esse dado sugere que as relações sociais de aceitação/rejeição em sala de aula se compõem de forma muito semelhante entre as escolas estudadas. Esses resultados facilitaram a interpretação de que os diferentes níveis econômicos e sociais das escolas, o número de alunos que atendiam e a infra-estrutura que possuíam não produziram diferenças significativas nas relações de aceitação/rejeição dos alunos. Dados dessa natureza não foram encontrados na literatura, o que impossibilitou comparações.

Os participantes perceberam mais presença de situações indicadoras de agressividade na situação familiar que na escolar. Esse dado, de certa forma, está de acordo com o de Abramovay e outros (1999), os quais mostraram que, para os jovens, a escola não era local de muita violência; no entanto, se contrapõe a esse mesmo trabalho, no qual os jovens informaram a família como local de não-violência, o que, talvez, se deva ao fato de que no âmbito popular agressão está mais associada ao físico que ao comportamento verbal. Ao lado disso, a maior presença de agressividade na família concorda com o estudo de Meneghel, Giuglian e Falceto (1998), no qual foi constatado que as punições físicas graves, freqüentes ou ocasionais, foram acontecimentos presentes em mais da metade dos estudantes, com maior 
porcentagem entre alunos de escolas públicas, mas também presentes em alunos de escolas particular, em um índice que pode ser considerado alto (37\%).

Apesar da maior quantidade de relatos de percepção de agressividade familiar, as diferenças entre as escolas foram atribuídas ao acaso, em razão da análise de variância. Esse dado sugere que a criança da escola particular não se percebe mais agressiva em situação familiar que as crianças das escolas públicas. De certa forma, sugere uma discrepância com os resultados do estudo citado anteriormente ou, pelos menos, seria importante investigar se as crianças cujas famílias apresentam altos graus de agressividade também são percebidas pelos outros e se percebem a si mesmas como agressivas, dado esse bastante interessante para se ampliar a compreensão do fenômeno da banalização da agressividade.

Por outro lado, o mesmo não ocorreu para as escalas de agressividade escolar e geral. Nos dois casos houve significância nas diferenças de média. Foram encontrados dois subgrupos, e o comum a ambos foi que as escolas A e D apresentaram menor agressividade declarada e as escolas E e B, maior agressividade. Nesse sentido, há indicativo de que a percepção que as crianças têm de sua agressividade difere também em razão de a escola ser pública ou privada, pois as crianças da escola particular se perceberam como mais agressivas que as crianças de duas das escolas públicas.

O fato que mais chamou a atenção foi que havia uma expectativa, em razão da literatura, de que as escolas serem maiores, com maior pobreza, indisciplina de estudantes, periféricas e com professores menos comprometidos com seu trabalho poderia ser critério para maior ou menor presença de agressividade. Assim, esperava-se uma seqüência entre as escolas de A, B, D, E,com indicativo de maior a menor agressividade. Não obstante, enquanto a escola D e a escola A realmente tiveram uma baixa percepção de agressividade, por sua vez, a escola E teve uma alta percepção de agressividade, quando era esperado que fosse baixa, e a escola B esteve dentro das expectativas. Esses resultados são indicativos de que alguns elementos estão interagindo nessas escolas, produzindo algumas percepções que podem ou não estar distorcidas. Alguns pontos que mereceriam ser investigados para elucidar esse quadro seriam: se a percepção que os outros têm do nível de agressividade dos alunos é similar à percepção de agressividade que os alunos têm de si; se a agressividade encoberta é avaliada, ou se somente a agressividade exposta é levada em consideração quando se está avaliando; e se a convivência com a agressão faz com que as pessoas não se percebam como agressivas, por exemplo.

As correlações entre as medidas sociométrica e de agressividade foram significativas para agressividade escolar e geral nas quatro escolas estudadas, favorecendo a interpretação de que, quanto maior a aceitação social, menor a agressividade declarada pelo estudante. De certa forma, esse dado corrobora outros estudos, entre os quais o de Dodge, Bates e Pettit (1990). Apesar disso, as correlações foram baixas, apoiando a afirmação de que nem todas as crianças agressivas se relacionaram com colegas problemáticos, nem também são rejeitadas por seus pares (Bierman, Smoot \& Aumiller, 1993; Coie, Terry, Lenox, Lochman \& Hyman, 1996, entre outros). No entanto, não se pode negar a tendência descrita por Newcomb, Bukowski e Pattee (1993) de que a maior agressividade das crianças foi associada à rejeição por colegas.

Considerando-se que as correlações, apesar de significativas, foram baixas, estudou-se se grupos extremos em termos de aceitação/rejeição entre pares se diferenciariam em termos de agressividade. Analisando-se escola por escola, apenas na escola B as escalas de agressividade escolar e geral diferenciaram os grupos extremos. Esse resultado novamente sugere que nem toda criança que se percebe como agressiva na escola é rejeitada por seus pares, o que poderia ser interpretado de duas maneiras, ainda que pesquisas sejam necessárias para seu aprofundamento. Uma das interpretações é o fato de o estudante ser rejeitado indicar uma banalização da violência, como informaram Rodrigues (1994), Costa (1993) e Cardia (1997) em suas pesquisas em escolas brasileiras. Uma outra é que as crianças agressivas também podem ser queridas por seus pares, a despeito de seu comportamento. Por exemplo, o estudante com comportamento agressivo, mas em situação de autodefesa, pode não ser percebido negativamente. Também, tem-se que considerar seu controle e uso para alcançar objetivos socialmente aceitos em contraposição à agressividade, consequiência de desorganização e respostas reativas para frustrações ambientais e interpessoais.

Finalmente, é interessante trazer à baila que, na escola, a agressão, geralmente, é realizada por um grupo conhecido de intimidadores que vitimam sistematicamente grupos específicos de colegas (Perry, Williard \& Perry, 1990). Os intimidadores, por volta de $7 \%$ a $15 \%$ dos estudantes, são mais agressivos, fisicamente mais fortes, maiores que seus pares e freqüentemente meninos (Olweus, 1993). Olweus relatou que os realizadores e os alvos da agressão na 
escola correm o risco de prisão e problemas de desempenho na escola, respectivamente.

A agressividade dos intimidadores sói se manifestar com estudantes não agressivos. Em conseqüência, boa parte dos intimidadores se agrupam com outros jovens agressivos. A continuidade desse agrupamento foi associada ao fracasso escolar e à evasão no estudo de Coie, Terry, Lenox, Lochman e Hyman (1996). Ao lado disso, há que se considerar que o padrão de problemas de comportamento mostrado por muitas crianças agressivo-rejeitadas (desatenção, afetividade negativa e reação de raiva) é indicativo de deficiências na elaboração das interações e elas correm o risco de ajustamento escolar pobre, mais do que a média de escolares evadidos, habilidades sociais deficientes para resolver problemas e alta taxa de indicação de problemas de saúde mental, como foi observado por Cox e Gunn (1980).

Estudos dessa natureza não foram encontrados na literatura brasileira. Esse fato pode ser indicativo de que muito da problemática ainda está por ser explorad e analisado à luz das condições socioeconômicas e seu reflexo na escola pública brasileira.

\section{REFERÊNCIAS}

Abramovay, M.; Rua, M. G.; Waiselfisz, J. J. \& Andrade, C (1999). Gangues, galeras, chegados e rappers. Rio de Janeiro: Garamond.

Araújo, M. C. A. (2000). Vivências escolares de jovens de um bairro da periferia de Belo Horizonte. Dissertação de Mestrado Não-Publicada, Programa de Pós-Graduação em Educação da Universidade Federal de Minas Gerais, Belo Horizonte.

Bierman, K. L., Smoot, D. L. \& Aumiller, K. (1993). Characteristics of aggressive-rejected, aggressive (nonrejected), and rejected (non-aggressive) boys. Child Development, 64, 139-151.

Boivin, M. (1998). Aggression, peer relations, and the development of social adjustment. Symposium of the International Society for the Study of Behavioral Development, Switzerland.

Boulton, M. J. \& Underwood, K. (1992). Bully victim problems among middle school children. British Journal of Educational Psychology, 62, 73-87.

Cairns, R. B., Cairns, B. D., Neckerman, H. J., Ferguson, L. L. \& Gariepy, J. (1989). Growth and aggression: 1. Childhood to early adolescence. Developmental Psychology, 25, 320-330.

Camacho, L. I. (2000). Violência e indisciplina nas práticas escolares de adolescentes. Tese de Doutorado, Programa de Pós-Graduação da Faculdade de Educação da Universidade de São Paulo.

Candau, V. (1999). Escola e violência. Rio de Janeiro: DP\&A Editora.

Cardia, N. (1997).Violência urbana e a Escola. Revista contemporaneidade e educação. Rio de Janeiro, IEC, 2, 26-69.
Codo. W. (Org.) (1999). Educação: carinho e trabalho. Petrópolis: Editora Vozes.

Coie, J. D., Terry, R., Lenox, K., Lochman, J. \& Hyman, C. (1996). Childhood peer rejection and aggression as predictors of stable patterns of adolescent disorder. Development and Psychopathology, 7, 697-713.

Costa, E. H.. C. (1993). A trama da violência na escola. Dissertação de Mestrado Não-Publicada, Instituto de Estudos Avançados em Educação da Fundação Getúlio Vargas, Rio de Janeiro.

Costa, M. R.(2000). Eu também quero falar. Um estudo sobre infância, violência e educação. Dissertação de Mestrado NãoPublicada, Programa de Pós-Graduação em Educação da Universidade Federal do Rio Grande do Sul.

Cox, R. \& Gunn, W. (1980). Interpersonal skills in the schools: Assessment and curriculum development. Em D. Rathjen \& J. Foreyt (Orgs.), Social competence: Interventions for children and adults (pp. 113-132). Elmsford, NY: Pergamon Press.

Dodge, K. A., Bates, J. E. \& Pettit, G. S. (1990). Mechanisms in the cycle of violence. Science, 250, 1678-1683.

Dubow, E. F. (1988). Aggressive behavior and peer social status of elementary school children. Aggressive Behavior, 14, 315-324.

Grondlund, N. (1950). The accuracy of teacher judgments concerning the sociometric status of 6th grade pupils. Sociometry, 13, 329-357.

Guimarães, M. E. (1995). Escola, galeras e narcotráfico. Tese de Doutorado Não-Publicada, Programa de Pós-Graduação em Educação Brasileira da Pontifícia Universidade Católica de São Paulo do Rio de Janeiro.

Huesman, L. R., Eron, L. D., Lefkowitz, M. M. \& Walder, L. O. (1984). The stability of aggression over time and generations. Developmental Psychology, 20, 1120-1134.

ILANUD - Instituto Latino americano das Nações Unidas para a prevenção do delito e tratamento do delinquiente (2000). Violência nas escolas. Revista do ILANUD, n. 16.

Kupersmidt, J. \& Coie, J. D. (1990). Preadolescent peer status, aggression, and school adjustment as predictors of externalizing problems in adolescence. Child Development, 61, 1350-1362.

Ladd, G. W., Kochenderfer, B. J. \& Coleman, C. C. (1997). Classroom peer acceptance, friendship, and victimization: Distinct relational systems that contribute uniquely to children's school adjustment. Child Development, 68, 1181-1197.

Lochman, J. E. \& Lampron, L. B. (1985). The usefulness of peer ratings of aggression and social acceptance in the identification of behavioral and subjective difficulties in aggressive boys. Journal of Applied Developmental Psychology, 6, 187-198.

Meneghel, S. N., Giuglian, E. J. \& Falceto, O. (1998). Relações entre violência doméstica e agressividade na adolescência. Cadernos de Saúde Pública, 2, 327-335.

Newcomb, A. F., Bukowski, W. M. \& Pattee, L (1993). Children's peer relations. A meta-analytic review of popular, rejected, neglected, controversial, and average sociometric status. Psychological Bulletin, 113, 1, 99-128.

Ollendick, T., Oswald, D. \& Francis, G. (1989). Validity of teacher nominations in identifying aggressive, withdrawn, and popular children. Journal of Clinical Child Psychology, 18, 221-229. 
Olweus, D. (1991). Bully-victim problems among school children: Basic facts and effects of a school-based intervention program. Em K. Rubin \& D. Pepler (Orgs.), The development and treatment of childhood aggression (pp. 85-128). Hillsdale, NJ: Erlbaum.

Olweus, D. (1993). Bullying at school. Cambridge, MA: Blackwell.

Paim Costa, G. (2000). A repercussão da violência social no cotidiano escolar. Dissertação de Mestrado Não-Publicada, Programa de Pós-Graduação em Educação da Universidade Federal do Rio Grande do Sul.

Parke, R. D., Cassidy, J., Burks, V. M., Carson, J. L. \& Boyum, L. (1992). Familial contribution to peer competence among young children: The role of interactive and affective processes. Em R. D. Parke \& G. W. Ladd (Orgs.), Family-peer relationships: Modes of linkages (pp. 10-134). Hillsdale, NJ: Erlbaum.

Patterson, G. R. (1982). Coercive family processes. Eugene, OR: Castalia.

Perry, D. G., Williard, J. \& Perry, L. C. (1990). Peers' perceptions of the consequences that victimized children provide aggressors. Child Development, 61, 1310-1325.

Rigby, K. \& Slee, P. T. (1991). Bullying among Australian school children: Reported behavior and attitudes toward victims. Journal of Social Psychology, 131, 615-627.
Rodrigues, A. S. (1994). Aqui não há violência: A escola silenciada (Um estudo etnográfico). Dissertação de Mestrado Não-Publicada, Programa de Pós-Graduação em Educação Brasileira da Pontifícia Universidade Católica do Rio de Janeiro.

Santos, J. V. T. (Org.) (1999). Violência em Tempo de Globalização. São Paulo: Editora Hucitec.

Sisto, F. F. \& Bazi, G. A. P. (2000). Escala de Agressividade para crianças $e$ jovens (relatório técnico). Faculdade de Educação, Universidade Estadual de Campinas.

Sposito, M. P. (2001). Um breve balanço da pesquisa sobre violência escolar no Brasil. Educação e Pesquisa, 27(1), 87103.

Waiselfisz, J. J. (1998). Juventude, violência e cidadania: os jovens de Brasília. São Paulo: Cortez.

Recebido em 10/03/2004

Aceito em 30/07/2004

Endereço para correspondência: Fermino Fernandes Sisto. Rua Carlos Guimarães, 150, apto. 82, CEP 13024-200, Campinas-SP. E-mail: fsisto@nipnet.com.br 